\title{
IMPROVING TRAINING OUTCOMES THROUGH BLENDED LEARNING
}

\author{
Michelle Reece \\ Certified Medical Representatives Institute
}

Barbara Lockee

Virginia Polytechnic Institute and State University

\begin{abstract}
Blended learning is a prominent trend in corporate training that has implications for distributed learning across a range of venues and constituents. Typically defined as an instructional program offered through a combination of two or more delivery modes, blended learning utilizes a variety of approaches, including print-based materials, instructor-led training, and web-based training, to name a few. This article describes training strategies and techniques available through blended learning designs, such as pre-work, assessment strategies, and transfer activities. The authors outline the advantages and limitations of blended learning options and present a case study on how one organization, Certified Medical Representatives Institute (CMRI), made the shift to a blended approach in its course product line, highlighting both successes and challenges faced in the transition.
\end{abstract}

\section{KEYWORDS}

Blended Learning, Training Methods, Instructional Strategies

\section{WHAT IS BLENDED LEARNING?}

Blended learning is a prominent trend in corporate training that has implications for distributed learning across a range of venues and constituents. Mantyla [1] defines blended learning as the use of two or more presentation and distribution methods for the purpose of enhancing both the content and the learner experience. Blended learning utilizes a variety of approaches, including print-based materials, instructorled training, and web-based training, to name a few. This article describes training strategies and techniques available through blended learning designs and outlines the advantages and limitations of such options. Finally, the authors present a case study on how a nonprofit healthcare education organization, Certified Medical Representatives Institute (CMRI), made the shift to a blended approach in its course product line. The case study highlights both successes and challenges faced in the transition.

\section{WHY BLENDED LEARNING?}

The notion of blended learning is not a new one. Since the beginning of mediated instruction, course developers have sought to find the perfect combination of technology-based instruction and live, face-toface teaching. Computer-based training took hold in the 1970s and, more recently, networked learning environments proliferated via the internet have created the phenomenon known as e-learning, a movement that has attracted widespread interest within the corporate training sector. However, in a 2001 State of the Industry Report conducted by the American Society for Training and Development (ASTD), Mark Van Buren [2] indicated that the rate of e-learning adoption by U.S. companies fell significantly short of 
industry projections. These projections, made three years out, declined from 23.0 percent for 2000 to 19.8\% for 2001 and to $18.2 \%$ for 2002. Participants were growing less optimistic regarding e-learning implementation as development time and costs became issues of concern. Because of the resources required, Van Buren found that larger companies were more likely to have the capital needed to invest in such an approach to training. Follow-up interviews with benchmark industries suggested that declining enrollments in existing e-learning instruction were likely due to prior negative experiences that learners had had while engaged in an e-learning program.

An unanticipated trend identified by Van Buren was an increase in classroom-based training, a trend that was explained, oddly enough, as the result of an increase in the use of technology for training. Benchmarking companies indicated that training programs were combining technology-mediated instruction at the workplace with instructor-led training, which seems to reflect the increasing adoption of blended learning.

\section{WHAT ARE THE POSSIBILITIES?}

Although a variety of models exist to describe possibilities available through blended approaches to training [3, 4], we present opportunities afforded by blended instruction in terms of time and place. Synchronous forms of training are often associated with instructor-led events, although such instruction can be mediated as well. Synchronous sessions can be blended with asynchronous instruction for a number of different purposes. For example, prior to engagement with asynchronous learning, participants often attend face-to-face sessions for orientation to the learning environment as well as possible preparation for advanced content. For primary instructional delivery, synchronous approaches to teaching are essential when immediate interaction and feedback are necessary, when outcomes are related to interpersonal skills development and behavioral or attitudinal change, and when skills require demonstration or application by the instructor. Synchronous sessions are also used for post-instruction purposes, such as group debriefing, assessment strategies, and evaluation data collection.

Asynchronous forms of training can also be appropriate interventions when blended with synchronous instruction. Pre-work is a popular application of network-based training, used for a variety of purposes such as assessment of prior knowledge, the introduction of new content, and preparatory exercises prior to classroom-based instruction. Asynchronous e-learning can also be used for the delivery of primary course content, as it is appropriate for both self-paced, individualized content and group-based, collaborative activities. Additionally, asynchronous strategies are often employed for follow-up work or postinstruction purposes, such as practice or application of new knowledge, skills, or attitudes, or assessment functions such as examinations or projects based on classroom-delivered content.

Because so many possibilities exist, the choices are almost endless. A training program could be created to leverage the benefits of e-learning as well as the motivational attributes of face-to-face instruction. Concurrently, it would be possible to develop an equally effective program consisting only of synchronous or asynchronous experiences but utilizing differing delivery technologies. The case study presented later in this article describes a company that delivers all instruction asynchronously but through a mix of print, CD-ROM, and e-learning solutions.

\section{WHAT ARE THE ADVANTAGES?}

There are good reasons to leverage a blend of instructional strategies and delivery media. First, blended learning allows trainers to meet the diverse learning needs of their participants. The use of multiple types 
Improving Training Outcomes Through Blended Learning

of learning technologies and strategies addresses issues of both learning style preference and convenience. Some learners prefer auditory instruction, whereas others attend to print-based training more effectively. With regard to convenience, the company described in the case study that follows uses a variety of delivery mechanisms because its clients have expressed the need for learning materials that can be engaged in while driving or in flight. The company, Certified Medical Representatives Institute, responded with content in print and $\mathrm{CD}$, fulfilling needs related both to learning style and convenience.

Blended learning allows for the extension of training programs to address both the preparation of learners and the application of learning to the workplace upon completion of the training program. As mentioned earlier, blended methods can allow for the assessment of learners prior to the primary training instruction. Knowing the experience or knowledge of learners in advance provides instructional designers with the ability to develop content that maximizes learning outcomes. Also, blended learning can facilitate prework, be it classroom training or asynchronous learning, before primary instruction, making participants better prepared to achieve the intended training results. Transfer of new learning to the job setting is another issue that blended learning can address, providing opportunities for guided practice and feedback to ensure performance improvement in the workplace.

\section{WHAT ARE THE LIMITATIONS?}

Blended learning is not without its drawbacks. First, the training developer will need more planning time. When a program uses a variety of delivery modes and instructional strategies, a clearly conceived plan is essential for smooth implementation. Also, communication is critical, as training with varied events becomes more complex to manage and implement. Communication of the program plans and expectations to participants will help ensure participation and learner buy-in.

Another challenge faced by those who utilize blended approaches to training is "push back" from participants regarding time required for completion. Because asynchronous instruction can happen anytime and anywhere, many managers choose to have employees engage in training during non-work hours. It goes without saying that such training is better received by participants when managers provide time to complete the instruction at work [5]. Attrition can still be a problem even if time is provided for engagement in asynchronous learning. Learning management systems can assist with the tracking of learner progress so that instructors can follow up with those who may be having trouble with training completion. Using blended strategies makes participant monitoring even more imperative to guarantee training effectiveness.

\section{HOW DO I CHOOSE THE BEST MIX?}

With so many possibilities afforded by blended learning, choosing the right mix may seem like a daunting task. However, by following the standard instructional design process, training developers are likely to have a variety of solutions emerge as potential strategies for blended programs. First, the desired learning outcomes must be identified. Once the goals are outlined, an assessment of the learners and their needs should be conducted. At this point, developers would seek information regarding prior knowledge and experiences, learning preferences, learning environment, and so forth. Such information will enable designers to choose appropriate instructional methods and correlate delivery modes to support methods. Given the availability of many instructionally sound choices, training developers can then make decisions based on matters of learner preference, development feasibility, and expense. 


\section{A CASE STUDY: THE CERTIFIED MEDICAL REPRESENTATIVES INSTITUTE}

The Certified Medical Representatives Institute (CMRI) is an independent nonprofit educational organization that provides continuing education, professional development, and certification for nonmedical staff in the healthcare industry. CMRI's curriculum of more than forty courses helps leading healthcare organizations and sales professionals stay current on critical industry-related advancements. The CMRI curriculum is delivered via distance learning to more than 10,000 students across the United States and Puerto Rico.

Media types used in CMRI courses include print-based text, audio CD-ROM, and browser-enabled or CD-ROM multimedia formats. The methods used by CMRI for delivering education and testing have evolved over the years to meet the needs of both students and the training departments of client companies. This evolution has been driven by the growth in technology, the use of e-learning and blended learning, training initiatives by customers, and student demand for alternative learning solutions.

\section{A. Background}

In the late 1990s, the use of technology to deliver training was widely considered to be the wave of the future. Multiple start-up companies emerged in the marketplace, and established content development firms began to look at ways to incorporate technological advances into their product mix. As a leading provider of content to the pharmaceutical industry, CMRI received numerous requests from companies that wanted to convert its content into an electronic format. Many of these so-called dot-com companies, however, had little or no instructional design experience, and many of their learning solutions consisted of simply converting printed text to an HTML format, effectively creating an electronic page-turner.

By early 1999, CMRI had made the decision to develop a prototype electronic course that would be used in a pilot program for a small Japanese pharmaceutical company. This pharmaceutical company had been given a directive to develop training materials that could be delivered via company laptops to sales representatives in the field. To develop this prototype, CMRI chose a small, fairly new technology firm that had some experience in the pharmaceutical industry. This firm used proprietary technology that allowed for internet updates to content but was not web-dependent, and it was able to capture student data for reporting purposes.

Despite these advantages, it quickly became evident that this company lacked the necessary instructional design and graphics capabilities to develop effective learning materials. In addition, the reporting functionality was unsatisfactory, and CMRI was unable to provide the complete reporting data that had been requested by the client. Most importantly, results of student surveys post-pilot indicated that students preferred learning via textbook to the electronic format as designed by this outside vendor. CMRI decided to continue to pursue other options for the conversion of text-based course material.

By early 2000, CMRI had interviewed many other vendors who were eager to demonstrate their products, and several agreed to convert part of the curriculum to an interactive format to allow CMRI to fully assess their capabilities. Many vendors had instructional designers, medical writers, and illustrators on staff, whereas others outsourced many of these functions. CMRI's criteria at this point consisted of content that could be delivered via a dial-up connection, incorporated multiple forms of instruction, was easy to navigate, and, most importantly, met the learning objectives of the course. The resulting submissions that CMRI reviewed throughout the year were highly varied, both in instructional format as well as pricing. 
Improving Training Outcomes Through Blended Learning

\section{B. Product Functionality}

By the end of 2000, CMRI had made a decision to form an alliance with a well-established e-learning company, Pedagogue Solutions, to convert its text-based curriculum to an electronic format. This company had experience developing e-learning programs for many pharmaceutical companies, had developed its first computer-based training initiative in 1988, and had been providing computer-based testing to the industry since 1984. Pedagogue's technical experience appealed to CMRI, which had discovered the importance of this expertise during its 1999 pilot conversion effort. At this time, CMRI had limited technology support of its own to offer.

In addition to its knowledge of the pharmaceutical industry, Pedagogue had an extensive staff of instructional designers, programmers, web designers, medical illustrators, and graphic artists. The company agreed to develop a prototype of a CMRI course utilizing its own two-tiered platform. The interface, or just-in-time, tier offered students a highly interactive series of exercises and instructional activities. Running in the background of this first tier was a second tier consisting of a full text tutorial. The full text tier of the course reinforced and further explained information that was presented in the justin-time tier. The full text segments could also be printed from the application.

Many of the vendor products CMRI reviewed had bells and whistles such as video clips and extensive use of audio that required multiple system requirements on student computers and were slow to download. The course that would be developed with Pedagogue could be delivered via CD-ROM, the internet, or a corporate learning management system (LMS). The course would be developed entirely in Flash, which allows text, graphics, and small audio clips to be downloaded quickly to a student's computer. The system requirements on the student side were fairly minimal, which appealed to CMRI because most of its students use company computers for learning and are not allowed to install non-company-approved applications.

At the time, this type of application seemed to be just what CMRI needed to address the needs of both students who preferred to learn through printed materials and students who wanted to learn through more interactive means. It also appeared to meet the needs of client companies for instruction that could be delivered anytime and anywhere. In April of 2001, CMRI and Pedagogue began the development of what would become CMR Online.

The first step in the development process was designing the interface template that would be used for all the courses that would be developed. It was important to CMRI that the design be user-friendly, easy for students to navigate, and readily recognizable as a CMRI course. The initial template design was reviewed extensively and sent to CMRI's curriculum committee, which is made up of academic and industry experts as well as instructional designers. CMRI also sought the guidance of its advisory board, which is made up of the training managers of client companies. The template design went through several versions as CMRI incorporated the suggestions and feedback of this group of advisors. One key change that was made during this process was to the second tier: it became apparent that using the full content in its entirety was not conducive to effective instruction in an electronic format. Instead, it was decided that a condensed version would be written by an instructional designer who specialized in medical writing. This condensed version would still tie directly to the just-in-time tier and specific learning objectives but in a much more streamlined fashion. This approach was more expensive and time consuming but much more instructionally sound.

By this time, CMRI's criteria for the electronic version of its course materials consisted of both instructional and technical factors. Because most of its students must take and pass a certification test, the 
content of CMR Online had to include the same information as the print-based course; therefore, the content had to be mapped to the certification exam to ensure that students could pass the exam using either format. CMRI also maintained that certain features were a must, including intuitive navigational buttons, a bookmark feature that would take students back to the point at which they exited the course, and a tracking feature for scoring all pre- and post-test scores. The technical criteria included the need for the course to be delivered via a dial-up connection or via a company laptop that likely had several layers of firewalls. These instructional and technical features were incorporated into the first product, Introduction to Pharmacology, developed and delivered in early 2002.

Since 2002, the product has continued to be refined. A decision was made to incorporate three distinct layers rather than the two-tiered approach that was originally designed. These layers include the just-intime layers, which are now called "quick learn" screens; a "detailed text” layer, which is the condensed version of the printed course; and the "explore further" layer, which includes graphics, animations, and interactive learning activities. Some additional enhancements made to the product since the launch of the first course include:

- All glossary terms are hyperlinked within the course to an audio-enhanced glossary, enabling students to hear the pronunciation of terms as well as learn their definitions.

- Navigation buttons glow when special features such as the detailed text or explore further activities are available to learners so that important information is not overlooked.

- All pre-test, post-test, progress check, and case study answers are hyperlinked so that students can simply click to move back to the appropriate area of the course for further study.

- Animations have a playback feature that allows students multiple opportunities to learn a complex process; this feature is also incorporated on quick learn screens to increase interactivity.

- A scrolling feature was added to all pre-test, post-test, progress check, and case study answers, enabling CMRI to provide learners with more detailed feedback.

The enhanced version of the product was renamed CMR InterActive to more accurately reflect that the product was not just delivered online. CMRI also thought that this name would have a more positive connotation to students and client companies.

\section{Lessons Learned}

The first lesson CMRI quickly learned was that converting text-based materials to an electronic format and doing it well took much more time than originally anticipated. CMRI courses include many medical drawings, which had to be illustrated and, in some cases, animated. Each 150- to 200-page course also had to be rewritten in a condensed format, and the review and revision process was labor intensive. Programming also took a considerable amount of time, and if changes were made, the course had to be regenerated before a master CD could be produced, which resulted in another full review. Since launching the first course early in 2002, CMRI has completed an additional six blended courses, which is far fewer than it had earlier anticipated.

Another discovery CMRI made was that customers' views of what the end product should look like were not always consistent. For example, some customers wanted a lot of video and audio incorporated into the courses, but the company had decided early on not to incorporate these features because of bandwidth issues. Also, CMRI found a common misconception among clients that an electronic version can be more easily customized than a print-based version, which is not always the case. The company had to make a decision to develop the product that it believed was the most instructionally sound and would have the most appeal to the largest audience. 
CMRI also discovered that it was extremely important to build a cohesive team that included representatives from both its own ranks and those of Pedagogue. Because CMRI is located in Roanoke, Virginia, and Pedagogue is located in Princeton, New Jersey, this presented a challenge. Communication methods had to be established early on and adhered to by all team members. One method that worked well was to create an email alias of all team members at both companies so that when one project team member had a question or project update, all members were kept informed.

Another lesson learned was to be prepared for the multitude of technical issues that arise when delivering training via e-learning. Even if customers are aware of system requirements before purchasing a course, all kinds of system incompatibility problems can arise once the CDs are sent to the actual student users. In one case, a new version of the CD-ROM had to be generated in order to meet the older system requirements for the computers of one part of a field sales team.

CMRI also discovered that learner acceptance of e-learning was initially much more limited than previously thought, due in part to factors such as a previous poor experience with another product and a reluctance to give up the portability of the print-based course.

\section{Learning Survey Results}

In September 2003, CMRI surveyed its students to determine their learning preferences. The web survey was sent to 6,600 active students, and more than $1,100(+16 \%)$ sent in responses. The results were surprising as well as encouraging to the company. When students were told, "If given only one method to receive CMRI educational materials, please rank your preference," they chose computer-based training via CD-ROM in the same proportion as book or text, as shown in the figure below.

Favored Method of Delivery

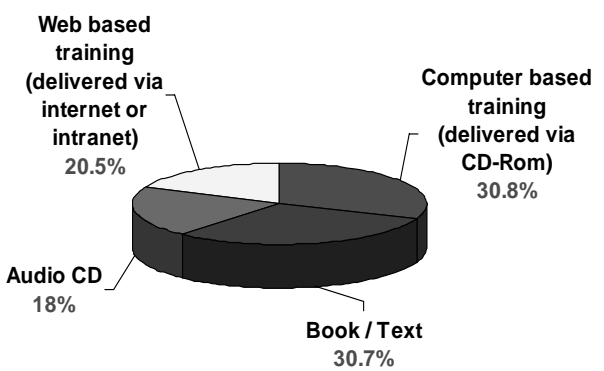

Figure 1. Favored Method of Delivery

Currently, CMRI course materials are packaged as a textbook and audio CD, and the company also wanted to gauge whether this was the preferred combination of delivery methods. The same students were told, "Given the opportunity to choose two methods of delivery, indicate your preferred combination." Again the results were similar, with students preferring a combination of computer-based training via CDROM and book or text, as shown in the figure below. 


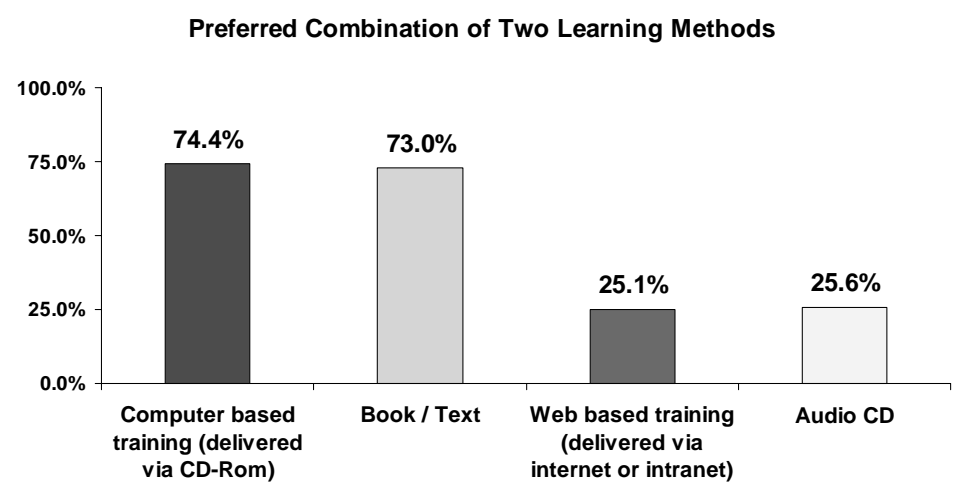

Figure 2. Preferred Combination of Two Learning Methods

Student demographic questions were also asked, including the age group of respondents. Because acceptance of e-learning has traditionally been associated with younger students, CMRI was surprised that the age groups showed little difference in learning and delivery preference. Although the largest group of respondents were in their thirties, those forty and over show the same levels of preference for computer-based training as for book or text, as shown in the figure below.

\section{Age of Respondents}

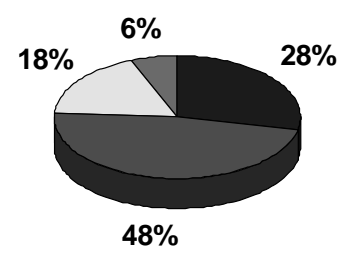

$\square$ 20-30 $\square$ 31-40 $\square$ 41-50 $\square 51+$

Figure 3. Age of Respondents

\section{E. Conclusion}

Although CMRI has been delivering asynchronous education for nearly forty years, it is only in the last few years that delivering course materials via alternative electronic methods has become a realistic venture for the company. The decision to convert its print-based materials into e-learning was not made lightly or without many bumps in the road. The company is still in the process of evaluating the use of CMR Interactive in its certification program.

\section{REFERENCES}

1. Mantyla, K. Blending e-Learning: The Power is in the Mix. Alexandria, VA: American Society for Training and Development, 2001.

2. Van Buren, M. State of the Industry: 2001 Report. Alexandria, VA: ASTD, March 2001.

3. Singh, H. Building effective blended learning programs. Educational Technology 43(6): November/December 2003.

4. Valiathan, P. Blended learning models. Learning Circuits: August 2002. http://www.learningcircuits.org/2002/aug2002/valiathan.html. 
5. Brooks, S. Blended training: Prerequisites and purple monkeys. Learning Circuits: June 2002. http://www.learningcircuits.org/2002/jun2002/elearn.html.

\section{ABOUT THE AUTHORS}

Michelle Reece is vice president of learning and curriculum development for the Certified Medical Representatives Institute. She is responsible for managing the development and revision of a diverse curriculum ranging from courses on science and medicine to business in healthcare and pharmaceutical management. The forty-plus courses in this curriculum are delivered to more than 10,000 students. Michelle has experience developing curriculum delivered in print-based and audio format as well as over the web. She has had articles published in NewSPoST magazine and the Journal of Pharmaceutical Marketing and Management. Michelle received an MA from Virginia Tech in curriculum and instruction with an emphasis in training and development. She is also a past president of the Valleys of Virginia Chapter of the American Society for Training and Development.

Barbara B. Lockee is an associate professor in the instructional technology graduate program at Virginia Tech. She teaches courses in distance education, training, and instructional design. Her research interests focus on instructional design and development issues within distributed learning environments, with a particular emphasis on evaluation design for e-learning. In the past six years, Dr. Lockee has written more than twenty-five publications for refereed journals and books regarding distance education and has presented at more than thirty national and international conferences and professional meetings. She currently serves as president of the Research and Theory Division of the Association of Educational Communications and Technology. 